\title{
GESTÃO DE PESSOAS E A CONSTRUÇÃO DA INOVAÇÃO ORGANIZACIONAL: UMA ANÁLISE DO PENSAMENTO GERENCIAL
}

\author{
People's administration and the construction \\ of the organizational innovation: \\ an analysis of the managerial thought
}

Envio 30.07.08 / Aceite 09.08.08

\author{
Janice Janissek de Souza ${ }^{1}$ \\ Antonio Virgílio Bittencourt Bastos ${ }^{2}$
}

\begin{abstract}
Resumo
O trabalho tem como objetivo analisar como as concepções de gestores organizacionais sobre a gestão de pessoas podem ajudar a explicar desempenhos diferenciados em termos de inovação. Para atingir o objetivo proposto, selecionaram-se duas empresas do ramo da indústria química que possuem padrões diferenciados de inovação, ou seja, são consideradas muito e pouco inovadoras. As informações foram coletadas por meio de entrevista semi-estruturada, realizada com dez gestores das organizações pesquisadas. Análise de conteúdo, com definição de categorias e subcategorias que sistematizam os conteúdos evocados pelos participantes foi o procedimento utilizado para analisar os dados. Como resultado do estudo, encontrouse que gestores inseridos no contexto mais inovador entendem que a inovação é alcançada por meio de uma gestão de pessoas que estimule a diversidade entre as pessoas; identifique e desenvolva talentos inatos e que possua um perfil comportamental baseado na busca de desafios e da aversão à rotina. Por outro lado, os gestores de empresas consideradas menos inovadoras concebem a inovação a partir de uma prática de gestão de pessoas que consiga reter pessoas com um perfil apropriado, tais como: não ter medo de errar, ser empreendedor, ser competente e possuir auto-estima.
\end{abstract}

Palavras-chave: Padrões de Inovação; Cognição Gerencial; Gestão de Pessoas; Práticas de Gestão; Perfil Inovador.

${ }^{1}$ Doutora em Administração pela Universidade Federal da Bahia. Departamento de Administração, Universidade Federal de Mato Grosso. Email: ricjanesalvador@terra.com.br

${ }^{2}$ Doutor em Psicologia pela Universidade de Brasília. Departamento de Psicologia, Universidade Federal da Bahia. Email: virgilio@ufba.br

Rev. Adm. UFSM, Santa Maria, v. 1, n. 2, p. 291-305, mai./ago. 2008 


\begin{abstract}
The work has as objective analyzes as the organizational managers' conceptions on the people's administration they can help to explain pattern differentiated in innovation terms. To reach to the proposed objective, two companies of the branch of the chemical industry were selected that possess differentiated patterns of innovation, in other words, they are considered a lot and little innovative. The information was collected through semi-structured interview accomplished with 10 managers of the researched organizations. Content analysis, with definition of categories and subcategories that systematize the contents evoked by the participants was the procedure used to analyze the data. As a result of the study it was that managers inserted in the most innovative context understand that the innovation is reached through an administration of people that stimulates the diversity among the people; identify and develop innate talents and that possesses a profile behavior based on the search of challenges and of the aversion to the routine. On the other hand, the managers of considered companies less innovators conceive the innovation starting from a practice of people's administration that gets to keep people with an appropriate profile, such as not having fear of wandering, to be enterprising, to be competent and to possess selfesteem.
\end{abstract}

Keywords: Innovation Patterns; Managerial Cognition; People's Administration; Practice of Administration; Innovative Profile.

\title{
1 Introdução
}

As interfaces entre a inovação organizacional e a gestão de pessoas têm sido exploradas em diversos trabalhos e fóruns acadêmicos. Neste sentido, dois aspectos principais justificam e definem a inter-relação existente entre os dois temas. O primeiro deles envolve a compreensão de que grande parte dos processos de inovação exige alterações significativas no perfil comportamental das pessoas no contexto de trabalho. O segundo aspecto refere-se às inovações específicas que se processam na forma como se concebe o vínculo que liga $o$ indivíduo às organizações (ROSSEAU e ARTHUR, 1999).

Para dar conta de compreender tais aspectos, pesquisadores e estudiosos da área utilizam diferentes abordagens teóricas e metodológicas. Uma das abordagens que crescentemente tem sido utilizada é a visão construtivista da inovação (SWAN, 1995; ZUBOFF, 1994; ORLIKOWSKI e GASH, 1994). De um modo geral, nesta abordagem, considera-se que não há uma inovação independente das cognições das pessoas envolvidas (WEICK, 1995). Valoriza-se, então, a idéia de que as ações dos seres humanos se baseiam na construção de significados, na avaliação de interesses e em escolhas. Apoiados em tais pressupostos, busca-se, no presente artigo, compreender como as concepções e crenças de gestores organizacionais acerca da gestão de pessoas podem ajudar a explicar a construção de padrões diferenciados de inovação organizacional.

Para alcançar o objetivo proposto, organizou-se o presente artigo em três partes principais. A primeira explora os conceitos considerados mais importantes para compreender os temas abordados. Em seguida, discorre-se a respeito dos procedimentos metodológicos utilizados na investigação e, finalizando o artigo, apresentam-se e discutem-se os resultados do estudo, assim como as principais conclusões. 


\section{Revisão teórica}

Nesta etapa do trabalho, são apresentados os principais conceitos teóricos que fundamentam a investigação proposta. Para tanto, inicia-se com uma discussão a respeito da inovação a partir de uma visão construtivista, uma vez que ela se mostra como a mais congruente com o enfoque adotado para desenvolver a presente proposta de estudo. Em seguida, uma revisão do que tem sido considerado pela literatura como mais inovador em termos de gestão de pessoas também é explorada.

\subsection{A inovação organizacional como um processo de construção social}

No presente estudo, optou-se por adotar um enfoque contrastante com a visão determinística da inovação. Há um reconhecimento da importância do conhecimento e das crenças e concepções dos atores organizacionais, ou seja, dos processos cognitivos. Assim, considera-se central que a compreensão dos resultados da implementação de novas idéias e práticas envolvam o entendimento de processos cognitivos (SWAN, 1995).

Diversos autores têm destacado a importância do conhecimento dos processos cognitivos no fenômeno da inovação. Berneker (1987) entende a tecnologia como conhecimento que é estruturado, codificado e pensado por outros e distingue tecnologia como um corpo de conhecimento sobre relações de causa e efeito de sistemas técnicos que são partes escolhidas desse corpo de conhecimento e estão envolvidos na construção de procedimentos, linguagens, software, layout físico, etc. Clark e Staunton (1989) vêem a inovação como uma variável que é socialmente construída e seu design se manifesta em diferentes formas para servir a diferentes contextos organizacionais. Nessa mesma linha de pensamento e destacando a dinamicidade dos processos de inovação, Weick (1993) sugere que a tecnologia é um equívoco, isto é, alguma coisa para a qual há diversas interpretações plausíveis. Portanto, elas requerem contínua estruturação e construção de sentido para serem gerenciadas. Os entendimentos humanos e os modelos mentais sobre eles são importantes na consideração de como uma dada inovação funciona. Para Weick (1993), não há uma organização real ou uma inovação independente das cognições das pessoas envolvidas. São as pessoas que desenham a tecnologia e a organização em consonância com as suas estruturas perceptivas e explicativas.

Lowstedt (apud SWAN, 1995) sugere que os pesquisadores que estudam as relações entre tecnologia e estrutura organizacional precisam olhar para cognições dos atores, pois consideram que a organização e a tecnologia são vistas como socialmente construídas por meio das pessoas que descrevem e interpretam a organização. Assim, a inovação não pode ser considerada uma força exógena imperativa sobre a natureza organizacional.

A visão construtivista da inovação também é defendida por Grey (2004, p. 18), que critica o discurso hegemônico da mudança organizacional e salienta que:

\footnotetext{
as pessoas existem numa gama de estruturas de significado - inclusive as do individualismo, que permitem que elas experimentem sua ação como um atributo pessoal - das quais a organizacional é apenas mais uma. Essas estruturas de significado são indeterminadas, abertas, além de imprevisíveis em seus efeitos e prováveis causas de consequências não intencionais.
}

Utilizando a mesma linha de argumentação, Zuboff (1994, p. 51) destaca que é necessário considerar que ao se implementar inovações tecnológicas, tais como as relacionadas com a informação,

Rev. Adm. UFSM, Santa Maria, v. 1, n. 2, p. 291-305, mai./ago. 2008 
as ações dos seres humanos se baseiam na construção de significados, na avaliação de interesses e, com variados graus de consciência, em escolhas. É no domínio da escolha que a tecnologia revela um certo indeterminismo. Embora redefina o horizonte de possibilidades, ela não pode determinar quais escolhas serão feitas e com que intenções.

Um dos trabalhos que se utilizou do enfoque cognitivista para compreender processos de inovação foi o de Orlikowski e Gash (1994), que analisaram as concepções que usuários e projetistas de tecnologia da informação têm sobre tecnologia. Tais autoras assinalaram, no estudo, que um entendimento das interpretações que as pessoas fazem da tecnologia é crítico para entender a sua interação com ela. Assim, as pessoas controem sentido sobre a tecnologia e, nesse processo, elas desenvolvem concepções, expectativas e conhecimentos particulares. Ao examinar tais interpretações, Orlikowski e Gash (1994) consideraram também que diferentes grupos dentro das organizações podem ter diferentes estruturas de entendimento do que seja a tecnologia. Nesse sentido, as autoras introduziram a noção de congruência para descrever a natureza e extensão das diferenças entre tais grupos. No caso do estudo desenvolvido por Orlikowski e Gash (1994), os dois diferentes grupos analisados foram os dos projetistas e dos usuários da tecnologia da informação, constatando que os dois grupos tinham entendimentos diferenciados em relação à tecnologia da informação.

Um outro trabalho que se utiliza de uma visão construtivista de inovação é o desenvolvido por Geppert, Williams e Matten (2003). Os autores analisaram como um conjunto de práticas de gestão, implementadas em subsidiárias de empresas alemãs e inglesas, em diversas partes do mundo, sofreram um processo de interpretação e de construção social que foi amplamente influenciado pelas características da cultura local de cada empresa. Geppert, Williams e Matten (2003) mostraram que as práticas gerenciais não são uma simples imposição de uma racionalidade global ou de uma racionalidade organizacional, mas estão sujeitas a um processo de interpretação, no qual racionalidades contextuais diferentes desempenham um papel importante.

Sintetizando o que foi explorado nesta seção, destaca-se que a forma como os indivíduos percebem e interpretam a realidade onde se inserem influencia a sua ação no ambiente social. Tal pressuposição é bastante clássica dentro dos estudos da cognição humana e social. Da mesma maneira, é válido afirmar também que a forma como os gestores agem em relação à gestão de pessoas é resultante de um processo de pensamento e ação, no qual as concepções e interpretações em relação a tais práticas exercem um papel importante neste processo (WEICK, 1995). Portanto, ao se considerar a idéia de que a inovação é um processo socialmente construído, conhecer as concepções que guiam as ações dos gestores das práticas e políticas de gestão de pessoas torna-se uma condição importante para se compreender tais processos.

\subsection{Modelos e práticas inovadores de gestão de pessoas}

Da mesma forma que é possível demarcar um conjunto de transformações e inovações mais recentes que ocorrem no modelo de gestão organizacional, alguns movimentos específicos que alteram a maneira de conceber o gerenciamento das pessoas no trabalho também são objeto de análise de estudiosos e pesquisadores da área (DUTRA, 2002; MOTA e VASCONCELOS, FLEURY e FISCHER, 2001; DAVEL e VERGARA, 2001, dentre outros). 
Um dos principais movimentos que sintetizam tais transformações é representado pela transição dos termos utilizados para denominar a forma como se dá a relação do indivíduo com a organização, ou seja, a noção de "Administração de Recursos Humanos" para "Gestão de pessoas".

A administração de Recursos Humanos (ARH) caracteriza-se pelo foco na visão racional, objetiva e normativa dos indivíduos, enfatizando a padronização e instrumentalidade de comportamentos das pessoas, enquanto desvaloriza manifestações da singularidade de cada sujeito, como seus interesses e expectativas (DAVEL e VEGARA, 2001). Trata-se, portanto, de uma abordagem que concebe o indivíduo como recurso que gera custos à organização. Nesse sentido, a ARH ganha uma perspectiva operacional cuja função é a de atrair, selecionar, manter, remunerar e desenvolver as pessoas mais adequadas às exigências do trabalho, tirando o maior proveito possível de seu trabalho (NEVES, 2002). Na verdade, a abordagem de ARH pode ser classificada em dois grandes paradigmas. Dependendo do enfoque mais funcionalista ou sistêmico que é dado às diversas atividades que se priorizam nesta abordagem, elas adquirem nuanças diferenciadas, sem, contudo abandonar sua identidade principal acima descrita. Segundo Dutra (2002), a ARH, entendida como um sistema, confere às funções especializadas uma visão mais inter-relacionada, envolvendo, inclusive, a relação destas com as estratégias mais globais da organização.

A difusão do termo e do modelo de "gestão de pessoas", tanto no campo científico quanto organizacional, reflete a incoerência da aplicação do modelo de ARH num contexto marcado por inúmeras mudanças políticas, econômicas, sociais e organizacionais. No entanto, nem todos os autores da área concordam que a expressão gestão de pessoas tenha se difundido de maneira similar entre os campos da teoria organizacional e do mundo empresarial. Fischer (2001), por exemplo, pontua que parece haver um maior emprego da expressão entre os especialistas nesta área, mais do que nos livros acadêmicos que se dedicam ao tema. De qualquer forma, o emprego de uma nova expressão parece designar um marco de redefinição que não só sobre um espaço de atuação profissional, mas, principalmente, uma forma diferente de conceber o ser humano. Este necessita atuar em organizações em que predominem novas formas de organização do trabalho, novas posturas profissionais, tipos de resultados e vínculos com a organização. Portanto, o uso da expressão "modelo de gestão de pessoas" implica considerar que a área de $\mathrm{RH}$ perdeu seu poder de monopólio sobre o comportamento humano nas organizações. Envolve aspectos que vão muito além da estrutura, dos instrumentos e das práticas normalizadas e abrange, então, tudo aquilo que interfere de maneira significativa nas relações entre os indivíduos e a organização (DIAS, 1995). Neste sentido, segundo Fleury e Fischer (2001, p. 56), o modelo de Gestão de Pessoas pode ser entendido como um "conjunto de políticas, práticas, padrões atitudinais, ações e instrumentos empregados por uma empresa para interferir no comportamento humano e direcioná-lo no ambiente de trabalho".

As práticas inovadoras que focalizam mais enfaticamente a gestão de pessoas nas organizações visam a modificar/alterar as práticas tradicionais dessa área. Assim, tanto as pressões por constante aumento de produtividade e qualidade quanto as que exigem um tratamento mais humano nos contextos de trabalho fazem com que práticas como a definição de cargos e formas de pagamento restritas; os direitos e deveres claramente diferenciados entre as cadeias de comando; os poderes de decisão centralizados no topo da organização dentre outras, não mais atendam aos anseios internos e externos à organização (ICHNIOWSKY et al.,1996).

Na classificação de Loiola, Bastos e Teixeira (2003), as práticas que podem ser incluídas no domínio da gestão de pessoas (Figura 1) são aquelas que envolvem uma combinação de 
organização do trabalho e políticas de administração de recursos humanos. Elas são adotadas com a finalidade de oferecer maior participação na tomada de decisão (empowerment), oportunidades para aprender novas habilidades (cultura aprendizagem) e um incremento nos incentivos financeiros para que se estimule maior dedicação e esforços para o alcance de metas. Envolvem também, normalmente, alguma forma de trabalho em equipe, círculos de qualidade e remuneração por desempenho (TEIXEIRA, 2006). Way (2002) e Kling (1995) comentam que este novo padrão de gestão de pessoas cria um Sistema de Trabalho de Alto Desempenho (HPWS - High Performance Work Systems).

\section{Práticas Inovadoras Gestão de Pessoas}

- Novas formas relacionamento social;
- Maior esforço e dedicação pessoas;
- Recompensas crescentes pela
dedicação;
- Uso da criatividade e força vontade;
- Maior auto-realização
- Maior grau de cooperação entre
trabalhadores;
- Maior participação nas decisões;
- Aumento da flexibilização
organizacional;
- Compartilhamento de idéias;
- Transferência controle aos
empregados

- Aumento bem-estar trabalhador;

- Oportunidade aprender novas habilidades;

- Remuneração por desempenho;

- Empowerment;

- Aumento confiança entre as pessoas e gerência;

- Tolerância a erros;

- Metas mais desafiadoras;

- Elevados padrões de excelência;

- Equipes auto-dirigidas;

- Pessoas motivadas intrinsecamente;

- Trabalho em equipe;

- Treinamento e desenvolvimento

Fonte: Adaptado de Loiola, Bastos e Teixeira (2003) e Teixeira (2006).

Figura 1 - Síntese das principais inovações no domínio das práticas de gestão de pessoas.

Em organizações que adotam esse sistema, há uma preocupação em selecionar, envolver, reter e motivar pessoas que respondam adequadamente às exigências e demandas por tais práticas: possuir e aplicar no trabalho habilidades superiores e que tal aplicação resulte em desempenho e rentabilidade para a organização (WAY, 2002).

Após a discussão dos principais conceitos envolvidos no presente trabalho, passa-se, a seguir, a descrever os procedimentos metodológicos utilizados para desenvolver o trabalho.

\section{Procedimentos metodológicos}

\section{- Modelo geral da pesquisa}

A presente pesquisa foi desenvolvida por meio de um estudo de natureza compreensiva sobre as concepções de gestores inseridos em organizações com diferentes padrões de inovação. O estudo de caso torna-se o método mais adequado, tendo em vista a natureza do objeto a ser investigado. Para Gerring (apud GONDIM et al., 2005), o estudo de caso é um estudo intensivo de uma unidade simples ou fenômeno delimitado, apropriado para elucidar uma ampla classe de unidades similares. Na mesma linha que destaca a singularidade do caso, Eisenhardt (1999) 
define estudo de caso como uma estratégia de pesquisa que foca sobre o entendimento da dinâmica presente dentro de um contexto ou cenário singular. Adicionalmente, a autora destaca que as principais finalidades do estudo de caso são a de descrever o fenômeno, gerar teorias e testá-las. Pode-se observar que os autores salientam, na definição do estudo de caso, a questão da singularidade que, segundo Gondim et al. (2005), é fundamental e ainda relativamente pouco explorada nos estudos sobre o tema. Nesse sentido, pode-se argumentar que a questão da singularidade, no presente estudo, manifesta-se, especificamente, na escolha de duas organizações com desempenhos diferenciados em relação aos seus padrões de inovação.

Considera-se também que a natureza preponderantemente qualitativa da pesquisa é coerente com a abordagem teórica adotada para o presente estudo. Nesse sentido, concebese o papel do ator como central na construção da inovação organizacional. Conforme afirma Birman (1991, p. 15), "reconhecer [...] a produção do sujeito na produção do objeto teórico é afirmar, ao mesmo tempo, que o sujeito empreende um trabalho de interpretação do real e que a interpretação é constitutiva da objetividade científica".

\section{- Participantes do estudo}

Foram selecionadas duas empresas industriais de grande porte, situadas na região da grande Salvador, classificadas como tendo diferentes padrões de inovação organizacional: muito e pouco inovadora. O critério para escolha das empresas tomou como base os resultados de um estudo anterior, que identificou a extensão de uso de 12 práticas inovadoras de gestão em um conjunto de 215 empresas industriais brasileiras (ver detalhes em PEIXOTO, 2004).

No Quadro 1, encontra-se uma caracterização das empresas pesquisadas por padrão de inovação.

Quadro 1 - Caracterização das empresas pesquisadas segundo o padrão de inovação

\begin{tabular}{|c|c|c|}
\hline $\begin{array}{c}\text { Padrão de } \\
\text { Inovação }\end{array}$ & Empresa & \multicolumn{1}{|c|}{ Caracterização } \\
\hline $\begin{array}{c}\text { Muito } \\
\text { Inovador }\end{array}$ & A & $\begin{array}{l}\text { Empresa dedicada exclusivamente à agricultura e pioneira em } \\
\text { biotecnologia. Seus principais produtos são os herbicidas, sementes e } \\
\text { produtos da biotecnologia. Em dezembro de 2001, foi inaugurada, no } \\
\text { Pólo Petroquímico de Camaçari, a primeira fábrica da empresa no Brasil. }\end{array}$ \\
\hline $\begin{array}{c}\text { Pouco } \\
\text { Inovador }\end{array}$ & $\mathrm{B}$ & $\begin{array}{l}\text { Multinacional norte-americana do ramo de produtos químicos } \\
\text { inorgânicos. A filial baiana é especializada na produção de dióxido de } \\
\text { titânio. Emprega mais de 4 mil pessoas globalmente e aproximadamente } \\
300 \text { na Bahia. É uma das líderes no seu setor de atuação. Devido ao } \\
\text { caráter de sua produção, a preocupação com o meio ambiente e com as } \\
\text { comunidades circundantes é constante, constituindo normas e } \\
\text { procedimentos altamente controlados. }\end{array}$ \\
\hline
\end{tabular}

Em seguida, selecionaram-se os participantes do estudo, constituídos por todos os empregados que ocupam cargo de gerência nas empresas pesquisadas. Na Tabela 2, encontrase uma caracterização dos participantes da pesquisa.

Conforme se pode observar na Tabela 1, existe uma diferença entre o número de entrevistados nas duas organizações pesquisadas. Portanto, na empresa considerada muito inovadora, foram pesquisados três gerentes; enquanto na empresa pouco inovadora, totalizouse um número de oito participantes. 
Tabela 1 - Caracterização do número de participantes do estudo por empresa, área, idade, tempo empresa e tempo de atuação como gestor

\begin{tabular}{|c|c|c|c|c|}
\hline \multirow[t]{2}{*}{ Informações } & \multirow[t]{2}{*}{ Especificações } & \multicolumn{2}{|c|}{ Empresa } & \multirow[t]{2}{*}{ Total } \\
\hline & & $\begin{array}{c}\text { Muito } \\
\text { Inovadora }\end{array}$ & $\begin{array}{c}\text { Pouco } \\
\text { Inovadora }\end{array}$ & \\
\hline \multirow[t]{8}{*}{ Gerência/área } & Saúde segurança & 1 & 1 & 2 \\
\hline & Supply & 0 & 1 & 1 \\
\hline & Jurídica & 0 & 1 & 1 \\
\hline & Produção & 1 & 1 & 2 \\
\hline & Manutenção & 1 & 1 & 2 \\
\hline & Financeira & 0 & 1 & 1 \\
\hline & Qualidade & 0 & 1 & 1 \\
\hline & Técnica & 0 & 1 & 1 \\
\hline \multicolumn{2}{|c|}{ Total } & 3 & 8 & 11 \\
\hline \multirow[t]{3}{*}{ Idade } & Entre 30 e 40 anos & 2 & 2 & 4 \\
\hline & Entre 40 e 50 anos & 1 & 3 & 4 \\
\hline & Mais 50 anos & 0 & 2 & 2 \\
\hline \multicolumn{2}{|c|}{ Total } & 3 & 7 & 10 \\
\hline \multirow[t]{5}{*}{ Tempo gestor } & Menos 5 anos & 0 & 1 & 1 \\
\hline & Entre 5 e 10 anos & 3 & 2 & 5 \\
\hline & Entre 10 e 15 anos & 0 & 2 & 2 \\
\hline & Entre 15 e 20 anos & 0 & 1 & 1 \\
\hline & Mais de 20 anos & 0 & 1 & 1 \\
\hline \multicolumn{2}{|c|}{ Total } & 3 & 7 & 10 \\
\hline
\end{tabular}

$\mathrm{Na}$ verdade, tal diferença reflete o tipo de estrutura hierárquica que caracteriza cada uma das organizações. Assim, na empresa mais inovadora, apenas três pessoas ocupam efetivamente cargo gerencial. Inicialmente, pensou-se que a diferença numérica traria algumas limitações em termos de análise e interpretação dos resultados. Dessa forma, decidiu-se ampliar o número de entrevistados na empresa mais inovadora, incluindo os ocupantes dos cargos imediatamente inferiores ao nível gerencial, que, na empresa, são denominados "líderes de equipe". No entanto, após algumas tentativas de entendimento para ampliar o número de pesquisados, a autorização para tal não foi concedida pela empresa.

Resolveu-se, então, assumir que as possíveis implicações da diferenciação estrutural entre as empresas seria um dado adicional que deveria ser incorporado como uma variável explicativa dos resultados encontrados. Além disso, por se tratar de um estudo de natureza 
predominantemente qualitativa e intensiva, o tamanho da amostra não representa por si só uma limitação do estudo. A representatividade foi garantida na medida em que o foco do estudo recaiu no nível gerencial e, dessa forma, todos os empregados deste nível das empresas participaram do estudo. Contudo, na empresa B, que tem um quadro gerencial composto de nove pessoas, um deles não pôde participar, em razão de dificuldade de agenda. No período da coleta de dados, esse gerente encontrava-se em constantes viagens, inclusive passando um período de tempo longo no exterior.

A coleta das informações ocorreu durante os meses de outubro e novembro de 2006. Utilizou-se uma entrevista semi-estruturada com os gestores de cada empresa participante do estudo. A entrevista centrou-se em uma única questão-chave, que investigou como se caracteriza a gestão de pessoas em uma empresa considerada inovadora na concepção dos gestores. À medida que as respostas foram sendo elaboradas, foram realizadas algumas intervenções do pesquisador com o objetivo de aprofundar e ou esclarecer algum ponto da resposta. Essa parte da coleta de dados foi gravada.

Segundo Rossman e Rallis (1998), nas entrevistas em profundidade, são desenvolvidas compreensões mais significativas pelo diálogo entre entrevistador e entrevistado co-construindo significados. Dessa forma, a entrevista leva ao mundo do entrevistado, até onde eles possam (ou escolham) verbalmente relatar o que está em suas mentes. O enfoque da entrevista semiestruturada ou semiguiada é tipicamente usado em estudos qualitativos. O propósito de entrevistas semidirigidas é extrair a visão de mundo do participante. Para tanto, o pesquisador desenvolve categorias ou temas a explorar, mas permanece aberto para explorar temas que o participante traga consigo. Assim, o pesquisador identifica alguns temas amplos, em forma de perguntas, para ajudar a descobrir os significados ou perspectivas do participante (ROSSMAN e RALLIS, 1998).

\section{- Análise de dados}

Os conteúdos, obtidos por meio das entrevistas gravadas, foram, primeiramente, transcritos na íntegra. Em seguida, procedeu-se uma leitura cuidadosa de todo o material. Após a leitura, separaram-se os conteúdos evocados que respondiam de forma mais direta a pergunta inicial da entrevista e que definiam as características de uma organização inovadora. Tais conteúdos foram agrupados em torno de grandes temas ou categorias. Em cada categoria definida, procurou-se também identificar a existência de subcategorias que pudessem, de alguma forma, especificar mais o entendimento do que é uma organização inovadora em termos de gestão de pessoas. O processo de análise de conteúdo foi realizado considerando os contextos estudados, ou seja, todos os conteúdos originados dos gestores inseridos no contexto muito inovador foram analisados separadamente dos conteúdos do contexto pouco inovador.

Coerentemente com uma análise de natureza mais qualitativa, nenhum conteúdo foi desprezado, mesmo que tenha aparecido na fala de apenas uma pessoa. No entanto, todas as categorias que compõem o esquema dos gestores, em cada contexto estudado, refletem a percepção de todos os seus integrantes. Assim, pressupõe-se que a consensualidade cognitiva é entendida não a partir de uma perfeita concordância, mas que há certa similaridade na forma como os indivíduos avaliam a informação. Embora Willey (1998) considere que o pensamento é, essencialmente, um conceito de nível individual, o autor assinala que as estruturas cognitivas são fortemente influenciadas pelas interações que os indivíduos estabelecem com os outros. Assim, tais interações originam idéias e/ou conceitos comumente compartilhados e, enquanto as interações ocorrem entre um número de diferentes indivíduos dentro de um dado grupo social, 
as idéias comumente compartilhadas começam a assumir uma existência própria independente de quem as criou (WILLEY, 1988).

Os conteúdos categorizados são apresentados na forma de mapas cognitivos de categorização (EDEN, 1988; EDEN e ACKERMAN, 1998; COSSETTE e AUDET, 1994).

\section{Resultados e discussão}

A apresentação e discussão dos resultados são realizadas com base no que mostra os mapas de categorização, construídos a partir dos conteúdos evocados nas entrevistas com os gestores pesquisados. Nesse sentido, dois mapas foram construídos: o dos gestores inseridos no contexto mais inovador (Figura 2) e aquele construído pelos gestores inseridos no contexto menos inovador (Figura 3).

Os gestores da empresa considerada mais inovadora (A) destacam que a gestão de pessoas numa empresa inovadora envolve a aceitação e o aproveitamento da diversidade, representada principalmente pela convivência com empregados mais jovens e com aqueles com mais tempo de empresa, simultaneamente, conforma ilustra a fala de um dos entrevistados "então você tem que ter um mix [...] pessoas prontas e pessoas novas [...] pessoas novas mais as antigas... as pessoas antigas já têm uma identidade com a organização [...] e as pessoas novas são o oxigênio da empresa".

Referem também a necessidade de se identificar e desenvolver talentos inatos, dar foco e direção, preparar tecnicamente para a função, além de possuir um planejamento efetivo de acompanhamento e desenvolvimento das pessoas: "o mais importante é você contratar bem e ter um plano efetivo de desenvolvimento e preparação profissional, técnica". A concessão do empowerment e a seleção de pessoas que tenham um perfil adequado para promover a inovação, ou seja, que sejam motivadas pelo desafio e que se incomodem com a rotina, também foram destacados nesta categoria ("buscar realmente pessoas [...] que não queiram entrar na rotina, ter sempre a mesma atividade acontecendo todo dia [...] é você buscar pessoas que se incomodam com isso"). 


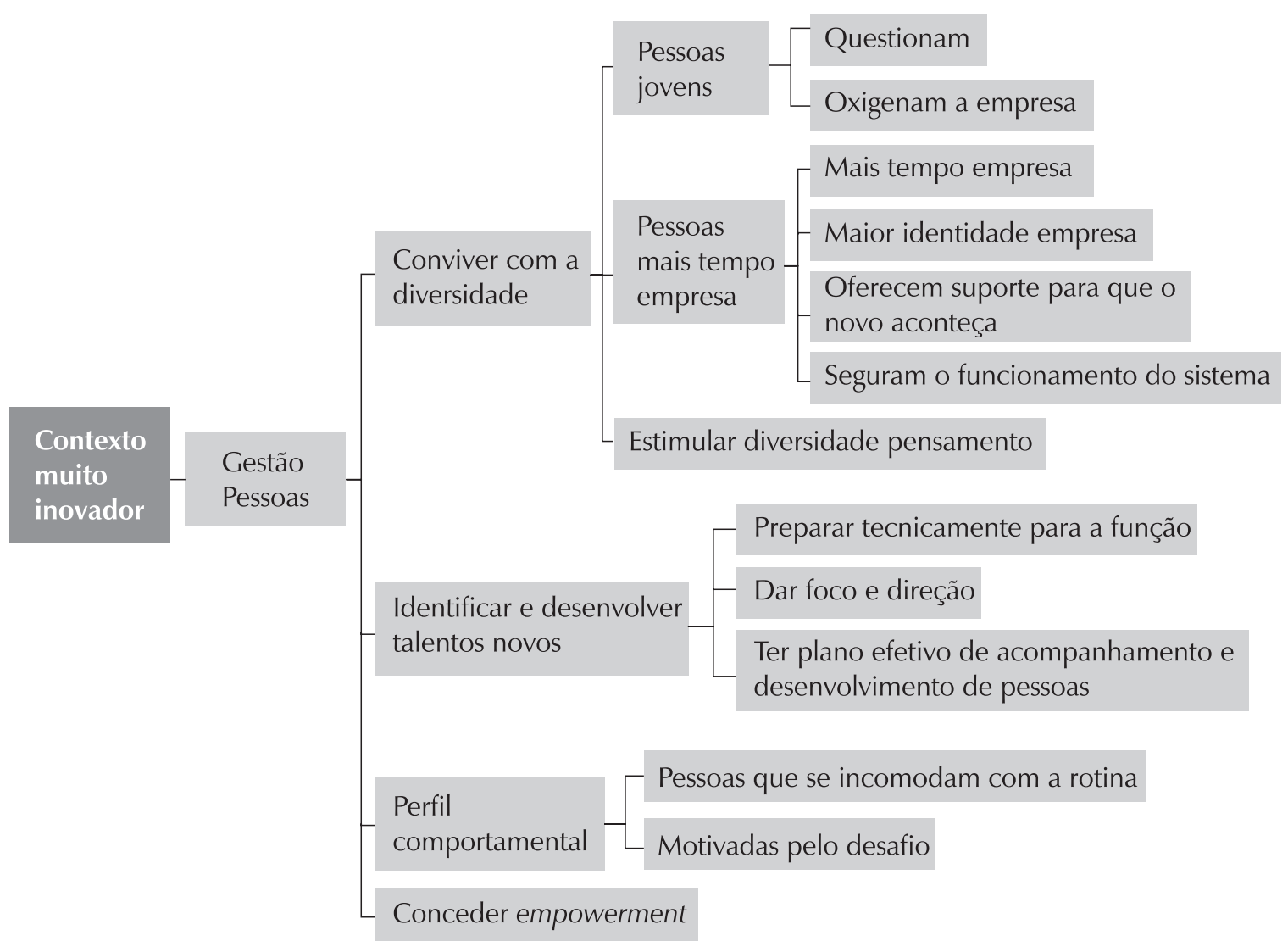

Figura 2 - Concepções gestão de pessoas na percepção de gestores inseridos no contexto muito inovador.

Os gestores integrantes da empresa considerada menos inovadora (B), por sua vez, enfatizaram a importância de se ter um perfil apropriado à inovação. Nesse sentido, dois grupos de características podem ser identificados.

O primeiro destaca a necessidade de a pessoa ser empreendedora, motivada por desafios e objetivos e ser competente tecnicamente. A fala de um dos entrevistados ilustra tal constatação: "tem que ser uma pessoa que tem firmeza de propósito, ou seja, tá realmente disposto a atingir objetivos". O segundo conjunto de característica envolve o preparo para aceitar a mudança, tais como, uma pessoa que não tenha medo de errar e que esteja preparada para mudar o sistema, conforme afirma um dos entrevistados: "a pessoa tem que ter a coragem de tentar algo novo, [...] de romper com o status quo". Destacam-se ainda o trabalho em equipe e a concessão de empowerment como estratégias importantes na gestão de pessoas ("uma organização inovadora é aquela que consegue utilizar bem seus recursos humanos, delegando autoridade [...], fazendo com que as pessoas se comprometam e se responsabilizem com a organização, [...] com pouca supervisão"). 


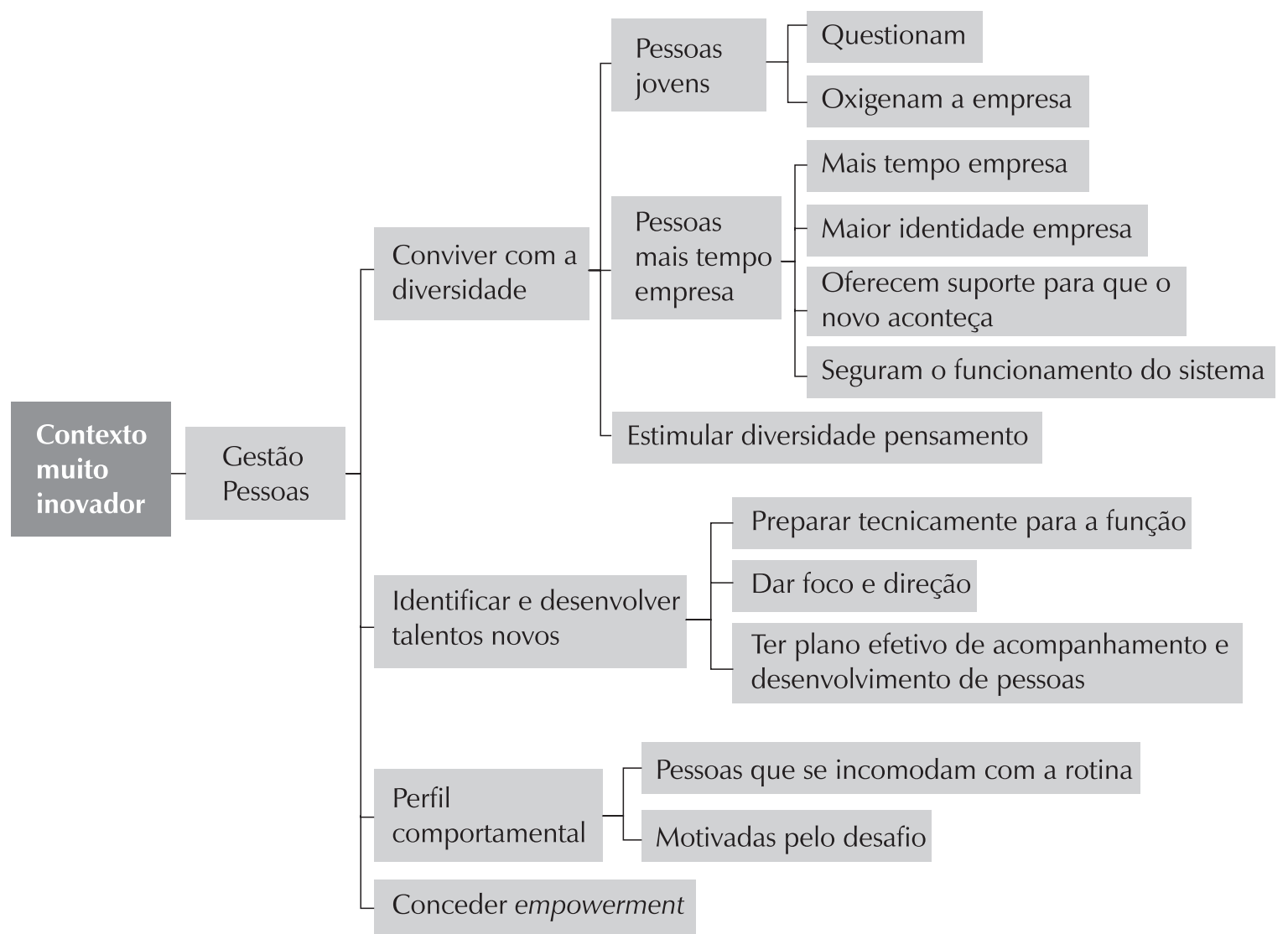

Figura 3 - Concepções gestão de pessoas na percepção de gestores inseridos no contexto pouco inovador.

Para os gestores da empresa "B", a gestão de pessoas em uma organização inovadora envolve também certas dificuldades. Assim, a resistência à mudança ("Muitas pessoas têm medo de errar, de mudar, não aceitam mudar"), a falta de qualificação e o despreparo das pessoas foram mencionados, como ilustra a fala de um dos entrevistados: "muitas pessoas são sistemáticas, não aceitam inovar [...] precisam ser trabalhadas e qualificadas". Esta pode, portanto, ser considerada uma diferença significativa quando se compara os dois esquemas. Além desta, a ênfase no perfil desejado também aparece com mais intensidade no esquema dos gestores da empresa menos inovadora.

Com base em tais conteúdos, pode-se inferir que a diferença fundamental entre os esquemas em relação à categoria "ênfase em pessoas" é que enquanto os gestores do contexto mais inovador entendem que uma empresa inovadora é aquela que busca um determinado perfil de pessoas e em cima deste prepara e desenvolve na direção desejada, os gestores do contexto menos inovador parecem colocar a responsabilidade pela inovação muito mais no perfil pronto, sem considerar a necessidade de desenvolvimento e direção. Talvez, por isso mesmo, associarem o processo de inovação às dificuldades de se gerenciar pessoas, principalmente àquelas relacionadas com a falta de qualificação e com o despreparo. Outro ponto que marca a diferença entre os esquemas de organização inovadora é a questão da diversidade, que aparece apenas no esquema dos gestores da empresa muito inovadora. Nesse sentido, tais gestores percebem uma aparente fonte de conflito negativo (novos $\mathrm{x}$ antigos) como oportunidade de se promover a inovação por meio da diversidade. Consideram, ainda, que a convivência entre os mais jovens e os mais antigos na empresa têm papéis complementares nos 
processos de inovação. Enquanto os mais jovens questionam e trazem novas e diferentes idéias, os mais antigos garantem o funcionamento do sistema e oferecem suporte à empresa enquanto a inovação não se traduz em resultados concretos.

Do ponto de vista teórico, tais resultados vêm confirmar o que outros estudos têm encontrado sobre o papel do pensamento e da cognição gerencial na construção da realidade organizacional. Nesse sentido, quatro aspectos principais podem ser identificados.

Primeiro ao atribuírem especial papel a um determinado perfil comportamental como desencadeador da inovação, o grupo de gestores da empresa "B" adota a perspectiva que Slappendel (1996) chama de individualista. Assume-se, assim, que certos indivíduos, dependendo das qualidades pessoais, são mais propensos a desenvolverem comportamentos inovadores independentemente das interferências estruturais.

Como segundo ponto, pode-se destacar que, de acordo com a abordagem da cognição organizacional e da visão mais construtivista dos processos de inovação, era esperado que as concepções se configurassem, em alguma medida, de forma diferenciada entre os contextos pesquisados (MOLDEN e DWECK, 2006). Tal distintividade entre as concepções confirma a importância de se analisar a inovação sob a perspectiva da cognição dos atores, privilegiando o entendimento de tal fenômeno como algo que se baseia na construção de significados, na avaliação de interesses e com variados graus de consciência em escolhas (ZUBOFF, 1994).

Outro ponto a destacar é a confirmação do pensamento de Clark e Staunton (1989), por exemplo, sobre a inovação organizacional. Para tais autores, a inovação se manifesta em diferentes formas e designs para servir a diferentes contextos organizacionais, produzindo, assim, também desempenhos e resultados diferenciados. Weick (1993) também concorda com tal linha de pensamento ao conceber que não há uma organização real ou um processo de inovação independente das cognições das pessoas, pois são eles que desenham as estruturas e a organização em consonância com as suas estruturas e esquemas cognitivos.

Finalmente, observou-se que os gestores não se referiram às práticas mais específicas que envolvem a gestão de pessoas. Com exceção do empowerment, que apareceu nos dois contextos, diversas outras práticas apontadas pela literatura (como as apresentadas por LOIOLA BASTOS e TEIXEIRA, 2003, por exemplo) não foram mencionadas. Tudo indica que, na visão dos gestores, quando se vincula gestão de pessoas com inovação se pensa prioritariamente em perfil atitudinal e comportamental como o elemento mais importante para se construir a inovação. Ou seja, a seleção de pessoas prontas como o desenvolvimento em direção a um perfil desejado foram enfatizados pelos dois grupos de gestores estudados.

\section{Conclusão}

Com base no objetivo central definido para o presente estudo, pode-se concluir que, no contexto mais inovador, predominam os conteúdos que destacam a necessidade de se preparar e desenvolver os talentos das pessoas de acordo com o perfil desejado e com o plano estratégico da organização. Já no contexto menos inovador, destaque especial é dado para o perfil comportamental necessário para promover a inovação sem, contudo, enfatizar-se a necessidade de a organização desenvolver e qualificar os empregados. Nesse sentido, concebese que as pessoas têm aptidões que precisam ser desenvolvidas e estimuladas (empresa " $\mathrm{A}$ ") ou têm uma aptidão inata para a inovação (empresa "B").

Diante de tais resultados é possível inferir que as concepções dos gestores sobre a gestão de pessoas pode ajudar a compreender a construção de padrões diferenciados de inovação organizacional. Ou seja, nas empresas em que há uma concepção de que as pessoas 
possuem um talento inato que necessita ser desenvolvido e acompanhado em direção ao que se espera do profissional parece contribuir, de forma mais significativa, para a construção de organizações mais inovadoras.

Por outro lado, empresas em que a concepção gerencial de gestão de pessoas envolve a idéia de que a empresa deve selecionar pessoas que tenham um perfil adequado e pronto para inovar sem que haja necessidade de aperfeiçoar e desenvolver aptidões parece contribuir para a construção de organizações menos inovadoras.

Certamente, tais conclusões devem ser mais sistematicamente testadas, seja através do uso de diferentes metodologias, seja por meio de outras abordagens teóricas. Sabe-se que o processo de construção de inovação é um fenômeno complexo que envolve muitas dimensões. No presente estudo, buscou-se priorizar e delimitar a compreensão da inovação sob a ótica do papel que o pensamento gerencial exerce na construção da inovação. Portanto, a pretensão não é encontrar explicações prontas e acabadas sobre o fenômeno, mas oferecer uma parcela de contribuição que possa elucidar e estimular novas investigações.

\section{Referências}

BERNEIKER, E. Understanding technical systems. Symposium on Management Training Programs, Implications of new technologies, Geneva (1987)

BIRMAN, J. Interpretação e representação na saúde coletiva. Physis: Revista de Saúde Coletiva, v. 1, n. 2, p. 7-22, 1991.

CLARK, P. A.; STAUNTON, N. Innovation in techonology and organization. London: Routledge, 1989.

COSSETTE, P.; AUDET, M. Qu'est-ce qu'une carte cognitive? In: COSSETTE, P. (Org.). Cartes cognitives et organisations. Quebec: Les Presses de I'Únivesité Laval et les Éditions ESKA, 1994. p.13-33.

DAVEL, E.; VERGARA, S. Gestão com pessoas e subjetividade. São Paulo: Atlas, 2001.

DIAS, J. M. G. Preditores do comportamento organizacional na EMATER/MG. 1993.

Dissertação (Mestrado em Administração)

- Centro de Pós-Graduação e Pesquisas em Administração - Faculdade de Ciências Econômicas - Universidade Federal de Minas Gerais, Belo Horizonte, 1995.
DUTRA, J. S. Gestão de pessoas: modelo, processos, tendências e perspectivas. São Paulo: Atlas, 2002.

EDEN, C. Cognitive mapping. European Journal of Operational Research, n. 36, p. 1-13, 1988.

EDEN, C.; ACKERMAN, F. Analysing and comparing idiographic causal maps. In: EDEN, C.; SPENDER, J. C. Managerial and organizational cognition: theory, methods and research. London: Sage, 1998.

EISENHARDT, K. M. Building theories from case research. Academy of Management Review, v.14, n. 4, p. 532-550, 1999.

FISCHER, André. Gestão de pessoas. São Paulo. Atlas, 2001.

FLEURY, M.T.L.; FISCHER, R. M. Cultura e poder nas organizações. São Paulo: Atlas, 2001. GEPPERT, M.; WILLIAMS, K.; MATTEN, D. The social construction of contextual rationalities in MNCs: an anglo-german comparison of subsidiary choice. The Journal of Management Studies, Oxford, n. 40, v. 3, p. 617, May 2003.

GONDIM, S. M. G. et al. Da descrição do caso à construção da teoria ou da teoria à exemplificação do caso? Uma das encruzilhadas 
da produção do conhecimento em administração e áreas afins. Organizações e Sociedade, v.12, n.35, p. 47-69, 2005

GREY, C. O fetiche da mudança. Revista de Administração de Empresas, v. 44, n. 1, p. 1025, jan./mar. 2004.

ICHNIOWSKY, C. et al. What works at work: overview and assessment. Industrial Relations, v. 35, n. 3, p. 299-333, July 1996.

KLING, J. High performance work systems and firm performance. Monthly Labor Review, v.118, n.5, p. 29-36, May 1995.

LOIOLA, E.; BASTOS, A. V.B.; TEIXEIRA, J. C. de A. (2003). A adoção de práticas inovadoras de organização e produção no Brasil. In: SIMPÓSIO DE ENGENHARIA DE PRODUÇÃO - SIMPEP, 10., 2003, Bauru. Anais... Bauru: FEB - UNESP, 2003.

MOLDEN, D. C.; DWECK, C. S. Finding "meaning" in psychology: a lay theories approach to self-regulation, social perception and social development. American Psychologist, v. 61, n. 3, p. 192-203, 2006.

MOTTA, F.C. P.; VASCONCELOS, I. F. G. Teoria geral da administração. São Paulo: Pioneira Thomson Learning, 2002.

NEVES, J.G. Gestão recursos humanos: evolução do problema em termos dos conceitos e das práticas. In: CAETANO, A.; VALA, J. (Orgs.).

Gestão de recursos humanos: contextos, processos e técnicas. Lisboa: $\mathrm{RH}, 2002$. p. 0430.

ORLIKOWSKI, W. J.; GASH, D. Technological frames: making sense of information technology in organizations. ACM Transactions on Information Systems, v. 12, p. 174-207, Apr. 1994.

PEIXOTO, A. (2004). O uso e a efetividade de modernas práticas de gestão do trabalho e da produção: um survey compreensivo da indústria brasileira. 2004. Dissertação (Mestrado em Administração) - Núcleo de Pós-Graduação em Administração - Universidade Federal da Bahia, Salvador, 2004.
ROSSEAU, D. M.; ARTHUR, M. B. Building agency and community in the new economic era. Organizational Dynamics, New York, v. 27, n. 4; p. 6-19, Spring 1999.

ROSSMAN, G. B.; RALLIS, S. F. Learning in the field: an introduction to qualitative research. Thousand Oaks: Sage, 1998.

SLAPPENDEL, C. Perspectives on innovation in organizations. Organization Studies, v. 17, n. 1, p. 107-129, 1996.

SWAN, J. A. Exploring knowledge and cognition in decision about technological innovation: mapping managerial cognition. Human Relation, v. 48, n. 11, p. 1230-1241, 1995.

TEIXEIRA, J. C. A. A dinâmica de adoção de práticas inovadoras e o desempenho dos adotantes: um estudo na indústria brasileira.

Tese de Doutorado em Administração, NPGA/ EA/Universidade Federal da Bahia, Salvador, 2006, 279p.

WAY, S. High performance work systems and intermediate indicators of firm performance within the US small business sector. Journal of Management, v. 28, n. 6, p.765-785, 2002.

WEICK, K. E. Sensemaking in organizations: small structures with larges consequences. In: MURNIGHAN, J. K. (Ed.). Social Psychology in Organizations. NJ: Englewood Cliff: PrenticeHall. p. 10-37, 1993.

WEICK, K. E. Sensemaking in organizations. London: Sage, 1995.

WILLEY, N. The micro-macro problem in social theory. Sociological Theory, v. 6, p. 254-504, 1988.

ZUBOFF, S. Automatizar/informatizar: as duas faces da tecnologia inteligente. Revista de Administração de Empresas, São Paulo, v. 34, n. 6, p. 80-91, nov./dez. 1994. 